\title{
„Kommt und seht den Ort" - sakrale Schrifträume im Sakramentar Heinrichs II.
}

Das in der Münchener Staatsbibliothek aufbewahrte Sakramentar Heinrichs II. stellt unter den vielen erhaltenen Prachthandschriften des Mittelalters ohne Zweifel eine Ausnahmeerscheinung dar. ${ }^{1}$ Es dürfte schwerfallen, ein zweites Sakramentar mit einem vergleichbar opulent geschmückten Messkanon zu nennen: Die auf den ersten 21 Pergamentblättern aufgebotene Fülle, Dichte und Varianz an farbenprächtigen Ornamenten ist regelrecht überwältigend. So kann es auch nicht verwundern, dass der Codex, der von Heinrich II., König des Ostfrankenreiches und späterem Kaiser, in Auftrag gegeben und im Skriptorium des Regensburger Klosters St. Emmeram hergestellt wurde, schon früh die Aufmerksamkeit von Kunstwissenschaftlern und Historikern auf sich zog. Die Forschungsliteratur allein zu den beiden Herrscherbildern am Anfang der Handschrift (fol.11v/r) ist kaum zu überblicken - ist schier „uferlos“, wie Elisabeth Klemm im entsprechenden Eintrag des 2004 veröffentlichten Bestandskatalogs der Münchener Staatsbibliothek urteilte. ${ }^{2}$ Vor diesem Hintergrund mag es erstaunen, wie wenig Beachtung bisher der Miniatur entgegenbracht wurde, die an prominentester Stelle direkt vor dem Text des Messkanons auf fol.15v zu sehen ist: dem ganzseitigen Bild des Heiligen Grabes (Abb.1).

Von breiten, üppigen Ornamentbändern gerahmt, wird hier das in den Evangelien geschilderte Ereignis am Ostermorgen präsentiert: Die Begegnung der Marien mit dem „Engel des Herrn“ vor dem leeren Grab Christi. ${ }^{3}$ Auf den ersten Blick erscheint dieses Bild, das die christliche Botschaft der Auferstehung propagiert und altbekannte Ikonographie-Muster tradiert, nicht ungewöhnlich und kaum der näheren

1 München, Bayerische Staatsbibliothek, Clm 4456. Pergament, 360 Blätter, 29,6×24,3 cm. Vgl. Klemm 2004, Kat.-Nr. 9; Gullath 2010; Dem Himmel entgegen 2012, Kat.-Nr. 9; Pracht auf Pergament 2012, Kat.-Nr. 39. Der Codex wurde im Auftrag Heinrichs II. kurz nach 1002 - dem Jahr der Königskrönung - in Regensburg (St. Emmeram) hergestellt, gelangte recht bald in den Bamberger Domschatz und wurde viel später, im Zuge der Säkularisation von 1803, nach München in die Staatsbibliothek überführt, wo er noch heute aufbewahrt wird. Als ursprünglicher Bestimmungsort der Handschrift wurde der Regensburger Dom, aber auch die Alte Kapelle in Regensburg in Betracht gezogen. Letztere wurde von Heinrich II. im Jahr 1002 als Hofkirche wiederhergestellt, mit reichen Schenkungen bedacht und 1009 dem Bistum Bamberg zugewiesen. Vgl. Pracht auf Pergament 2012, Kat.-Nr. 39.

2 Klemm 2004, 34. Vgl. hier auch die ausführliche Bibliographie.

3 Mt 27,57-28,20; Mk 15,42-16,8; Lk 23,50-24,53; Joh 19,38-21,25.

Dieser Beitrag ist im Heidelberger Sonderforschungsbereich 933 „Materiale Textkulturen. Materialität und Präsenz des Geschriebenen in non-typographischen Gesellschaften“ entstanden (Teilprojekt A05 „Schrift und Schriftzeichen am und im mittelalterlichen Kunstwerk“). Der SFB 933 wird durch die Deutsche Forschungsgemeinschaft finanziert.

๑ Open Access. () 2019 Tobias Frese, publiziert von De Gruyter. (c) BY-NC-ND Dieses Werk ist lizenziert unter der Creative Commons Attribution-NonCommercial-NoDerivatives 4.0 Lizenz.

https://doi.org/10.1515/9783110629156-003 
Betrachtung wert. Vordergründig scheint die Miniatur auch nur ein Thema zu wiederholen, welches der Einband der Handschrift, im zentralen Elfenbeinrelief unter der Kreuzigung, vorzeigt (Abb. 2). ${ }^{4}$

Vergleicht man die Miniatur allerdings mit diesem Relief, so fallen doch signifikante Unterschiede auf: In der Malerei nimmt der Grabbau einen wesentlich größeren, ja zentralen, Platz ein. Das farbenprächtige Monument dominiert geradezu die Szenerie. Zudem reduzierte der Illuminator die Zahl der Marien (zwei statt drei) ${ }^{5}$ und steigerte zugleich das hieratische, zeremonielle Moment: Die beiden Frauen stehen in erkennbar respektvollem Abstand zum göttlichen Boten. Die Vorderste der Marien schwenkt ein Weihrauchfass; der auf dem Sarkophagdeckel sitzende Engel hält einen goldenen Kreuzstab. Längere Bildtituli in goldenen Majuskeln rahmen die Miniatur und gliedern die Bildebenen. ${ }^{6}$ Insgesamt markiert die Miniatur dem Relief gegenüber eine Differenz: In Pracht und Würde überbietet das Innere das Äußere.

Am interessantesten aber ist der spezifische Ort des Osterbildes innerhalb des Codex selbst: Direkt am Anfang des Opfergebets platziert - zwischen Präfation und Messkanon (Abb.4) - muss es als „Kanonbild“ verstanden werden. Allein in dieser Funktion ist das Osterbild in der Buchmalerei ohne Vergleichsbeispiel und somit einzigartig - ein Umstand, der in der Forschung bislang kaum gewürdigt wurde. ${ }^{7}$ Dabei ist unübersehbar, dass die von Heinrich II. gestiftete Handschrift mit den überkom-

4 Elfenbeinrelief, Lothringen (Metz?), um 980/90. Der Einband wurde mehrfach restauriert; die Goldeinfassung ist neuzeitlich. Vgl. Gullath 2010, 13-15; Pippal 2010a; Dem Himmel entgegen 2012, Kat.Nr.9. Dass das Elfenbein zum Originaleinband gehörte, wird in der Forschung mehrheitlich angenommen, ist aber streng genommen nicht beweisbar. Zum Verhältnis von Vorder- und Rückdeckel des Bucheinbandes unter besonderer Berücksichtigung der vestimentären Dimension vgl. Ganz 2015, 131. 5 Dies entspricht dem Bericht des Matthäusevangeliums (Mt 28,1-20).

6 Auf dem Relief wird Schrift nur ganz oben, im Kreuztitulus, präsentiert: IHS NAZAREN(us) REX IVDEORV(m). Auf der Kreuzigungsminiatur auf fol.15r nimmt Schrift wesentlich größeren Raum ein. Mehrere Inschriften in Goldbuchstaben sind dem Purpurgrund eingeschrieben. Interessant ist dabei, dass in der Miniatur ausgerechnet die Tafel über dem Kreuz unbeschriftet blieb.

7 In der nach wie vor maßgeblichen Untersuchung von Rudolf Suntrup zu „Te igitur-Initialen und Kanonbildern in mittelalterlichen Handschriften“ wird das Osterbild des Sakramentars Heinrichs II. nicht thematisiert. Im entsprechenden Katalogeintrag zur Handschrift wird zwar die Kreuzigungsminiatur genannt, das Bild des Heiligen Grabes aber nicht einmal erwähnt. Vgl. Suntrup 1980, Kat.Nr. 107. Gleiches gilt für den Aufsatz von Victor H. Elbern zur „Illustration des Messkanons im frühen Mittelalter“, Elbern 1965 und für den Artikel „Kanonbild“ im Lexikon der christlichen Ikonographie. LCI, Bd.2, Sp. 492-495. Im 2010 publizierten Faksimilekommentar zum Sakramentar Heinrichs II. wird die Miniatur zwar erschöpfend beschrieben, die unorthodoxe Funktion als Kanonbild aber nicht angesprochen. Pippal 2010b, 109-113. Dies ist umso erstaunlicher, als bereits Hans Szwarzenski vor mehr als 100 Jahren die Miniatur im Kontext des Messkanons als ,ganz eigenartig und meines Wissens ohne Parallele“ charakterisierte. Vgl. Swarzenski 1901, 67. Im Ausstellungskatalog zur Regensburger Buchmalerei ist lapidar von dem im Kontext des Messkanons „ungewöhnlichen Thema(s) der Frauen am Grabe“ die Rede. Diese Beobachtung wird jedoch nicht weiter erläutert, geschweige denn vertieft. Regensburger Buchmalerei 1987, 27, Kat.-Nr.16, 32. Garrisson konstatiert zwar die außergewöhnliche Platzierung der Miniatur - bringt das Osterthema aber mit den beiden vorangehenden Herrscherdar- 


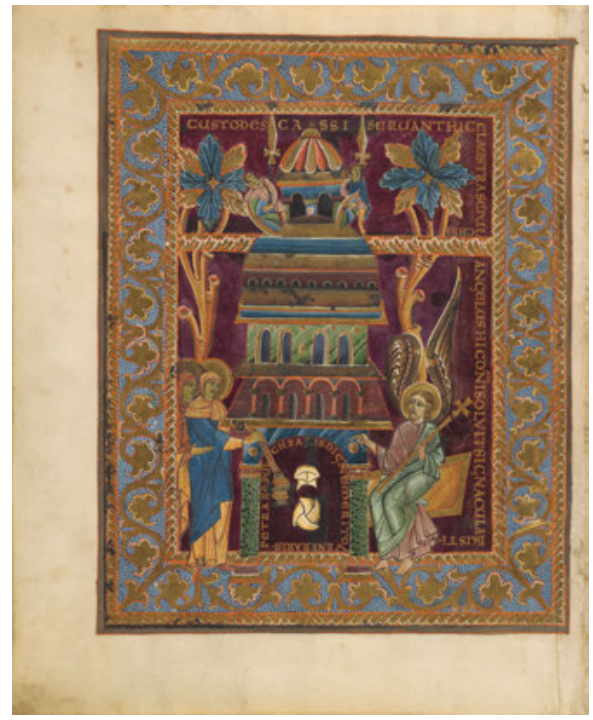

Abb.1: Bayerische Staatsbibliothek München, Clm 4456, fol. $15 \mathrm{v}$.

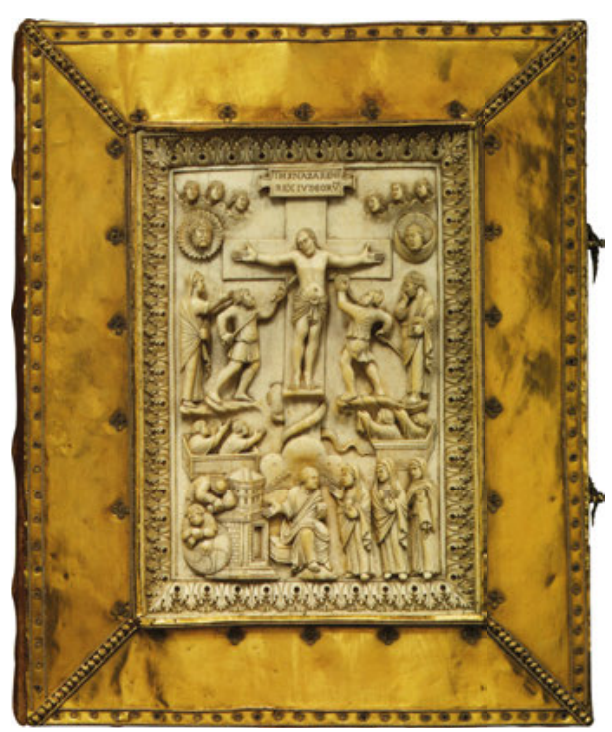

Abb. 2: Bayerische Staatsbibliothek München, Clm 4456, Vorderdeckel.

menen Darstellungskonventionen mittelalterlicher Sakramentare bricht. So erwartet ein mit diesen Konventionen vertrauter Rezipient nach dem Text der Präfation, die im triumphalen Sanctus (dem „Dreimalheilig“) kulminiert, das thematisch passende Bild der Maiestas Domini - direkt danach aber, zu Beginn des eucharistischen Opfergebets, das Bild der Kreuzigung. ${ }^{8}$ In der Heinrich-Handschrift wird diese Ordnung nun geradezu auf den Kopf gestellt: An die Stelle der Maiestas Domini tritt das Bild der Kreuzigung (Abb.3). Der dadurch bewirkte Überraschungseffekt ist umso größer, als diese Kreuzigung nicht einen Sieger über den Tod, sondern einen bereits gestorbenen Christus präsentiert und ebenso deutlich die Trauer der Assistenzfiguren unter dem Kreuz vor Augen führt. Die Klage erhält gar kosmische Dimensionen: Selbst die Personifikationen von Sonne und Mond wenden sich vom gemarterten Gottessohn ab und verdecken ihre Gesichter in Trauer. Auch wenn geläufige Zeichen der Heiligkeit bzw. Göttlichkeit nicht fehlen (Goldnimben, Kreuznimbus) und die Evangelistensymbole in den Ecken einen Hinweis auf die Maiestas des Gekreuzigten implizieren, ${ }^{9}$ so wird die zukünftige Herrlichkeit der Auferstehung im Bild gerade nicht antizipiert:

stellungen Heinrichs II. (und inhaltlich mit dessen angestrebter renovatio regni francourm) in Verbindung. Vgl. Garrisson 2012, 149.

8 Vgl. Frese 2010, 49-58; Kitzinger 2013; ausführlich Frese 2013.

9 Swarzenski 1901, 67, 74. Interessant ist, dass keine Nägel an Händen und Füßen sichtbar sind. Dennoch ist die Einschätzung Gude-Suckales nicht nachvollziehbar, dass die Haltung des Gekreuzigten dadurch „etwas Majestätisches bekommt“ und Christus insgesamt als „Triumphator über den Tod“ präsentiert wird. Kaiser Heinrich II. 1002-1024 2002, 272, Kat.-Nr. 112; vgl. auch Pippal 2010b, $107 \mathrm{f}$. 


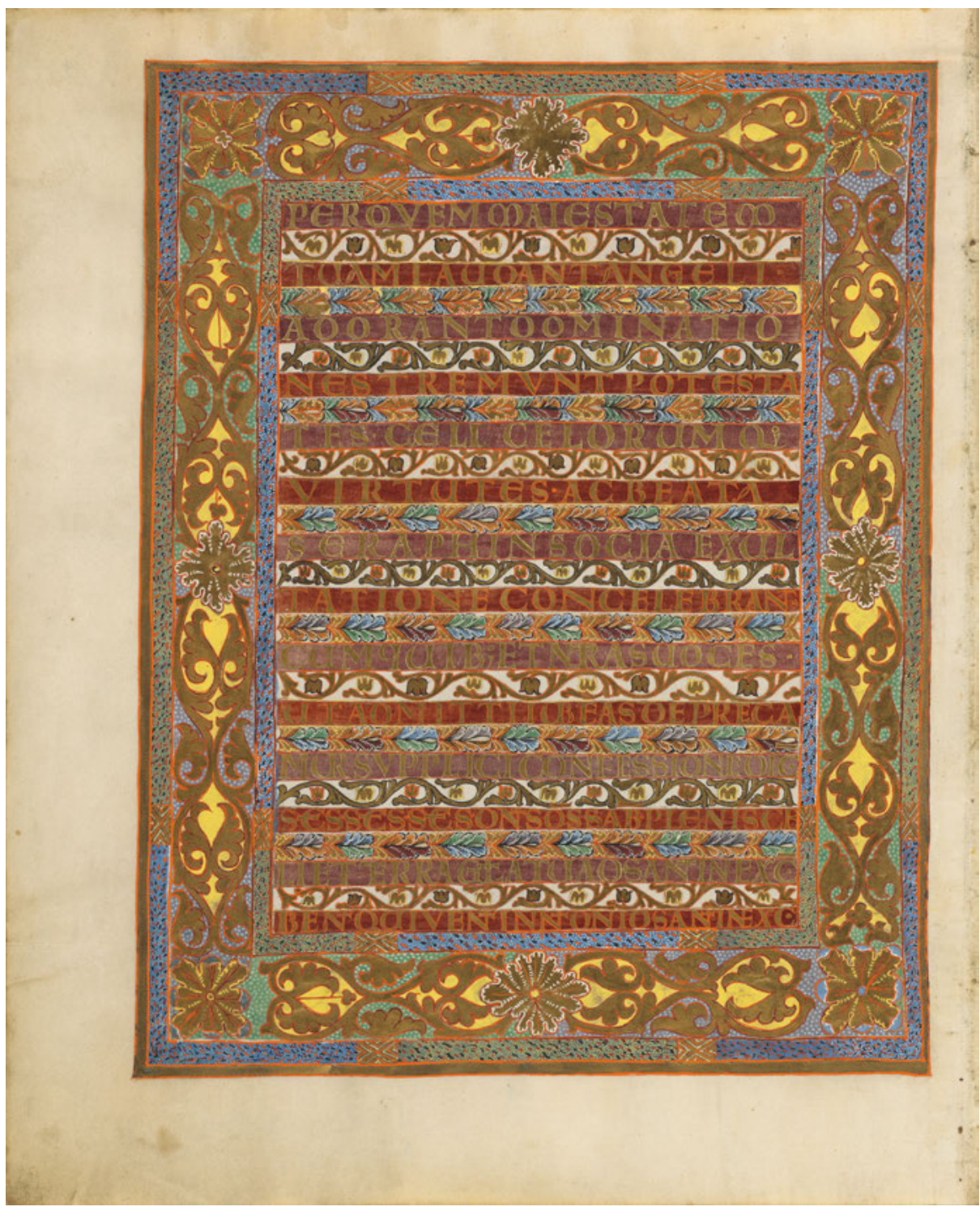

Abb. 3 (beide Seiten): Bayerische Staatsbibliothek München, Clm 4456, fol. 14v-15r.

Im Gegensatz zum Relief des Einbandes wird Christus - mit zur Seite gesunkenem Haupt, geschlossenen Augen und eingeschlagenen Daumen - auffallend deutlich als Toter gezeigt. Wie die Inschrift in großen griechischen Lettern postuliert, ist eben „die Kreuzigung“ (H CTAOV/ФР $\Omega$ PCIC, [sic!]) selbst das Thema.

Auf einer Doppelseite vereinigt, werden Sanctus-Text (fol.14v) und KreuzigungsBild (fol.15r) einander direkt zugeordnet. Das Resultat dieses ,Diptychons“ ist eine 


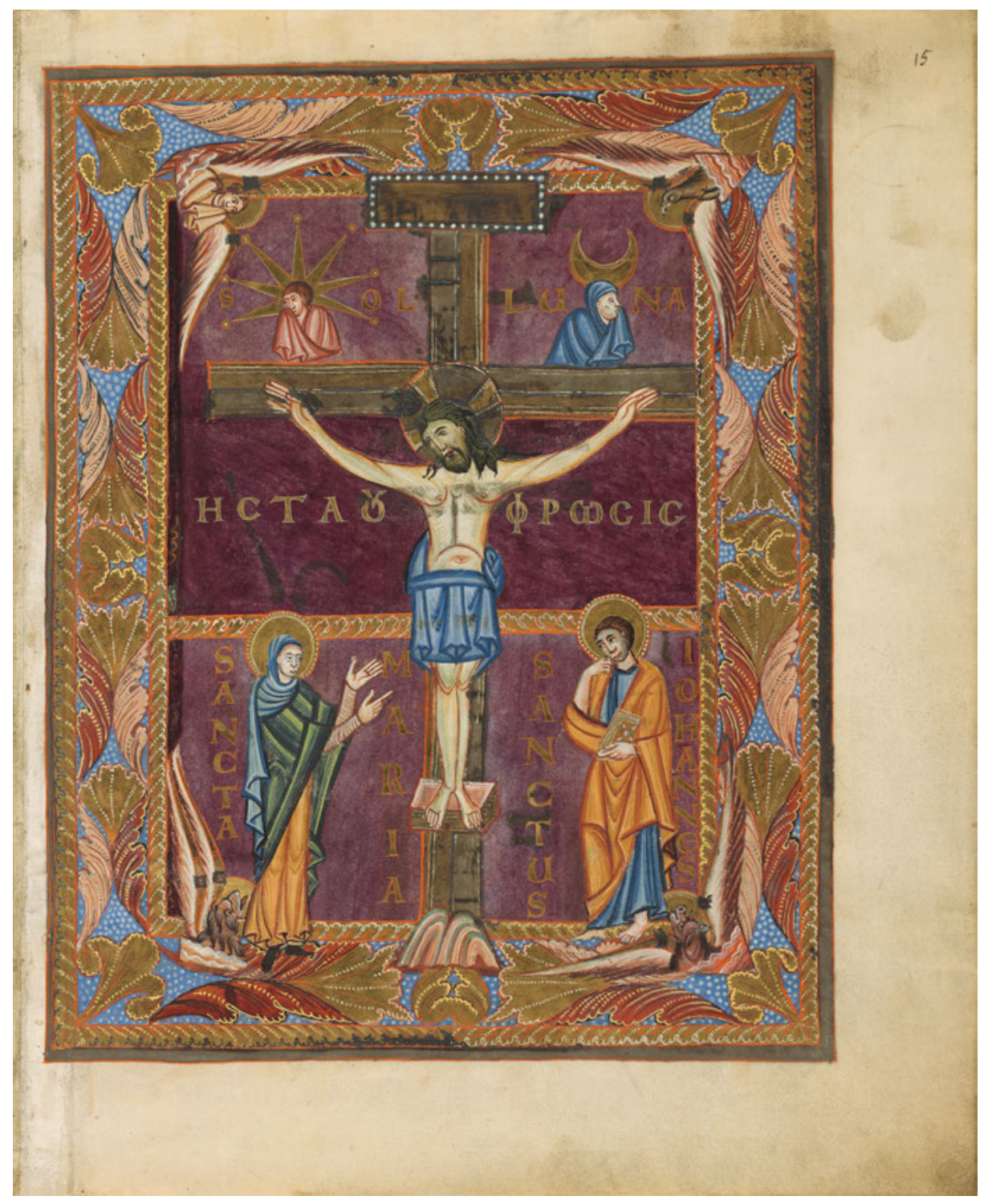

recht ungewöhnliche Text-Bild-Kombination: Der Jubel und Lobgesang der englischen Heerscharen gilt nicht dem im Himmel thronenden Gott, sondern dem am Kreuz gestorbenen Christus. Dies hat interessante Auswirkungen auf den semantischen Gehalt der Passions-Ikonographie selbst: Die in den Ecken der Miniatur eingestellten Evangelisten-Symbole lassen sich nun auch als die vier apokalyptischen Wesen verstehen, die das „Dreimalheilig“ singen. Und: Die Trauer des Bildes wird vom Jubel der Schrift begleitet. Es steht kaum zu vermuten, dass dies das unglückliche Resultat einer unbedachten Text-Bild-Redaktion war. Vielmehr kann angenom- 


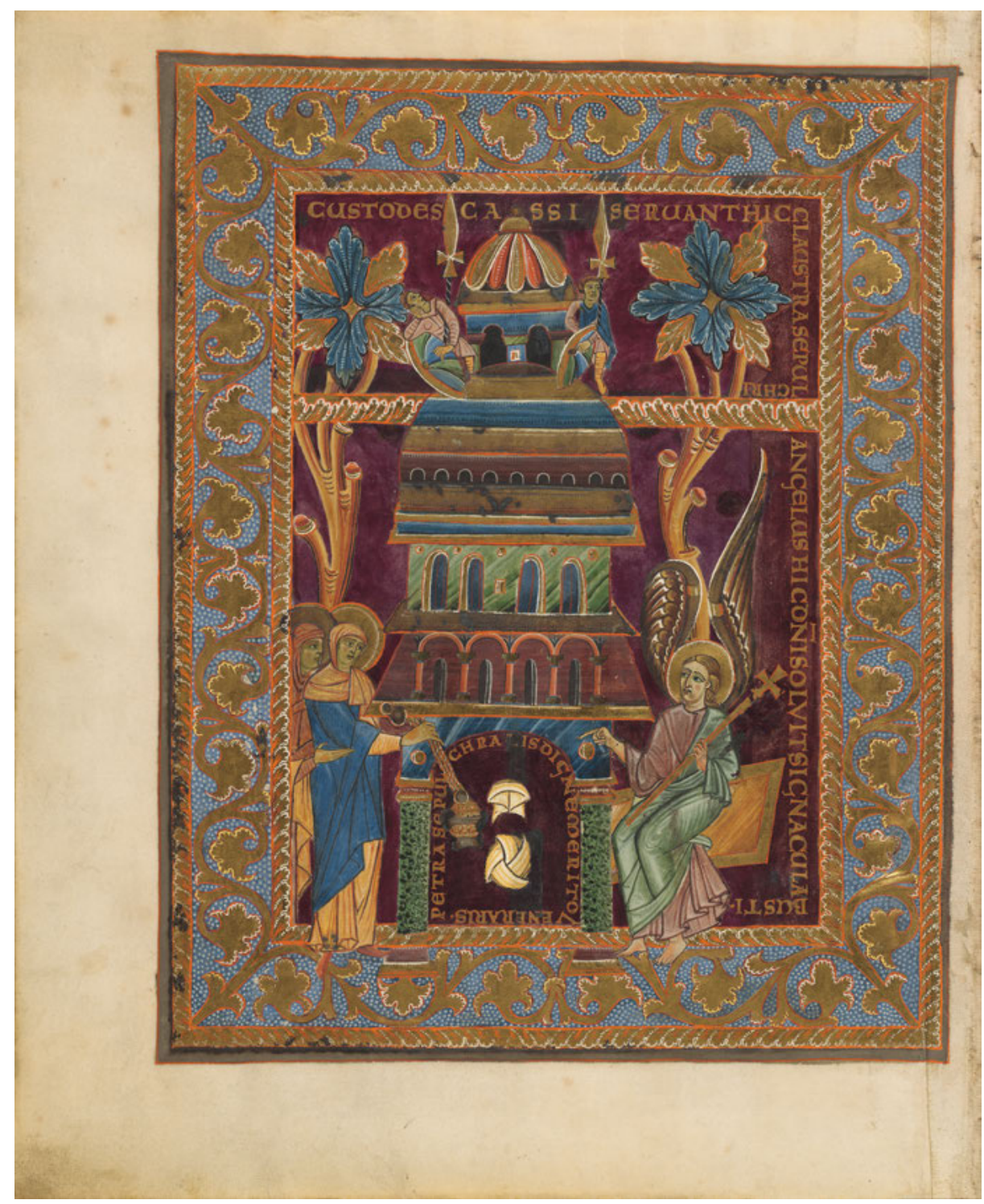

Abb. 4 (beide Seiten): Bayerische Staatsbibliothek München, Clm 4456, fol. 15v-16r.

men werden, dass diese ungewöhnliche Kombination vom königlichen Auftraggeber durchaus so gewollt war. Die entsprechende Botschaft lautet: Erde und Himmel mögen - wie in der Miniatur zu sehen - von Wehklagen erfüllt sein; caeli et terra sind aber dennoch - wie im Sanctus zu lesen - von der gloria Dei durchdrungen. Die drückende tristitia des Karfreitags wird von der ausgelassenen „Freude“ (exsultatio) der Engel gleichsam flankiert. Dem Kreuz des Todes wird imaginär der Thron 


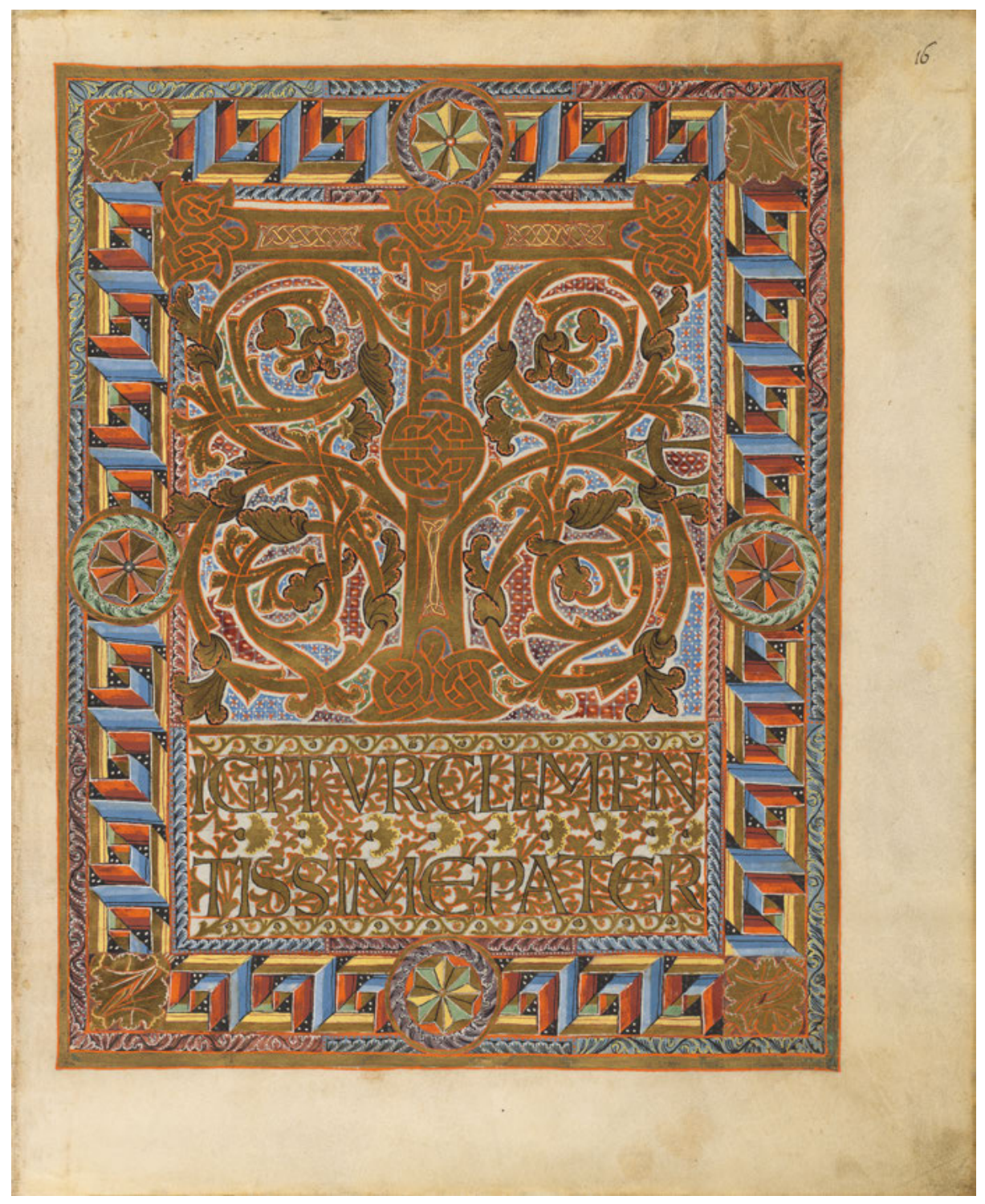

des lebendigen Gottes zugeordnet. Oder ist das Kreuz gar selbst als der Thron Gottes zu verstehen?

Blättert man nun weiter (Abb.4), wird man mit der nächsten Überraschung konfrontiert: Der Beginn des Opfergebets (fol.16r) wird von der Darstellung des leeren Grabes (fol.15v) begleitet - wie bereits gesagt ein in der Illumination frühmittelalterlicher Sakramentare singulärer Fall. Aber nicht nur der spezifische Ort, sondern 
auch die Miniatur selbst erweist sich bei näherer Betrachtung als recht originell. ${ }^{10}$ Dies betrifft allerdings weniger die Ikonographie als die Gestaltung des Layouts und den spezifisch ikonischen Einsatz von Schrift. So fällt auf, dass der goldene Blattfries, der die äußeren Grenzen der Miniatur markiert, sich im oberen Bereich einmal horizontal durchs Bildfeld zieht und im oberen Drittel ein querrechteckiges Feld ausspart (Abb. 5).

Hier sind die Wächter des Grabes zu sehen, die auf dem Dach des Grabes gleichsam ihren eigenen Raum zugewiesen bekommen. Diese Separierung der Wächter erinnert in auffälliger Weise an eine spätantike Elfenbeintafel aus dem frühen 5. Jahrhundert, an das sog. Trivulzio-Elfenbein, das im Mailänder Castello Sforzesco ausgestellt wird (Abb.6). ${ }^{11}$ Auch hier erstreckt sich die Palmetten-Rahmung nicht nur am äußeren Rand der Tafel, sondern durchschneidet diese horizontal - in diesem Fall auf halber Höhe (wodurch ein irritierendes Moment, eine Art Kippeffekt entsteht: ein Element der Architekturdarstellung, nämlich das Dachgesims des Mausoleums, fungiert zugleich als Rahmung der Tafel). Die beiden Wächter haben kurioserweise auf dem Dach Platz genommen, nehmen aber in Gestik und Körperhaltung deutlich Bezug auf das darunter stattfindende Ereignis. Ganz anders die Wächter in der ottonischen Miniatur. Diese scheinen nicht die himmlische Erscheinung darunter zur Kenntnis zu nehmen oder in irgendeiner Weise davon affiziert zu werden. Akkurat halten sie ihre Lanzen in die Höhe, lehnen sich auf ihre Schilde und scheinen gelangweilt ins Nirgendwo zu schauen. Fast hat man den Eindruck, der Soldat links habe die Buchstaben über sich entdeckt und versuche nun, diese zu entziffern und deren Sinn zu verstehen. Dies wäre insofern nachvollziehbar, als das Verständnis dieser Inschrift tatsächlich durch eine grammatikalische Doppeldeutigkeit erschwert wird. Im Ganzen ist hier zu lesen:

\section{CUSTODES CASSI SERUANT HIC / CLAUST / RA SEPULCHRI}

In der Forschungsliteratur werden, ohne nähere Erläuterung oder philologische Problematisierung, recht unterschiedliche Übersetzungen dieser lateinischen Inschrift vorgeschlagen: In dem von Gude Suckale-Redlefsen verfassten Katalogtext zur Bamberger Heinrichs-Ausstellung von 2002 heißt es knapp: „Die Wächter des leeren Grabes halten es in Gewahrsam““. ${ }^{12}$ In dem von Martina Pippal besorgten Kommentar zur Faksimileausgabe von 2010 ist dagegen zu lesen: „Hier bewachen die Wächter taub den Verschluss des Grabes“. ${ }^{13}$ Was ist nun richtig? Aufgrund der grammatikalischen Konstruktion des lateinischen Satzes ist diese Frage tatsächlich nur schwer zu beantworten. Interessant ist, dass das entscheidende Wort - das Adjektiv cassi - genau

10 Für eine ausführliche Beschreibung siehe Pippal 2010b.

11 Mailand, Castello Sforzesco. Civiche Raccolte di Arte applicata ed Incisioni, Inv.-Nr. 9. Höhe: 30,7 cm, Breite: 13,4 cm. Vgl. Brenk 2011.

12 Kaiser Heinrich II. 1002-1024 2002, 272, Kat.-Nr. 112.

13 Pippal 2010b, 113. 

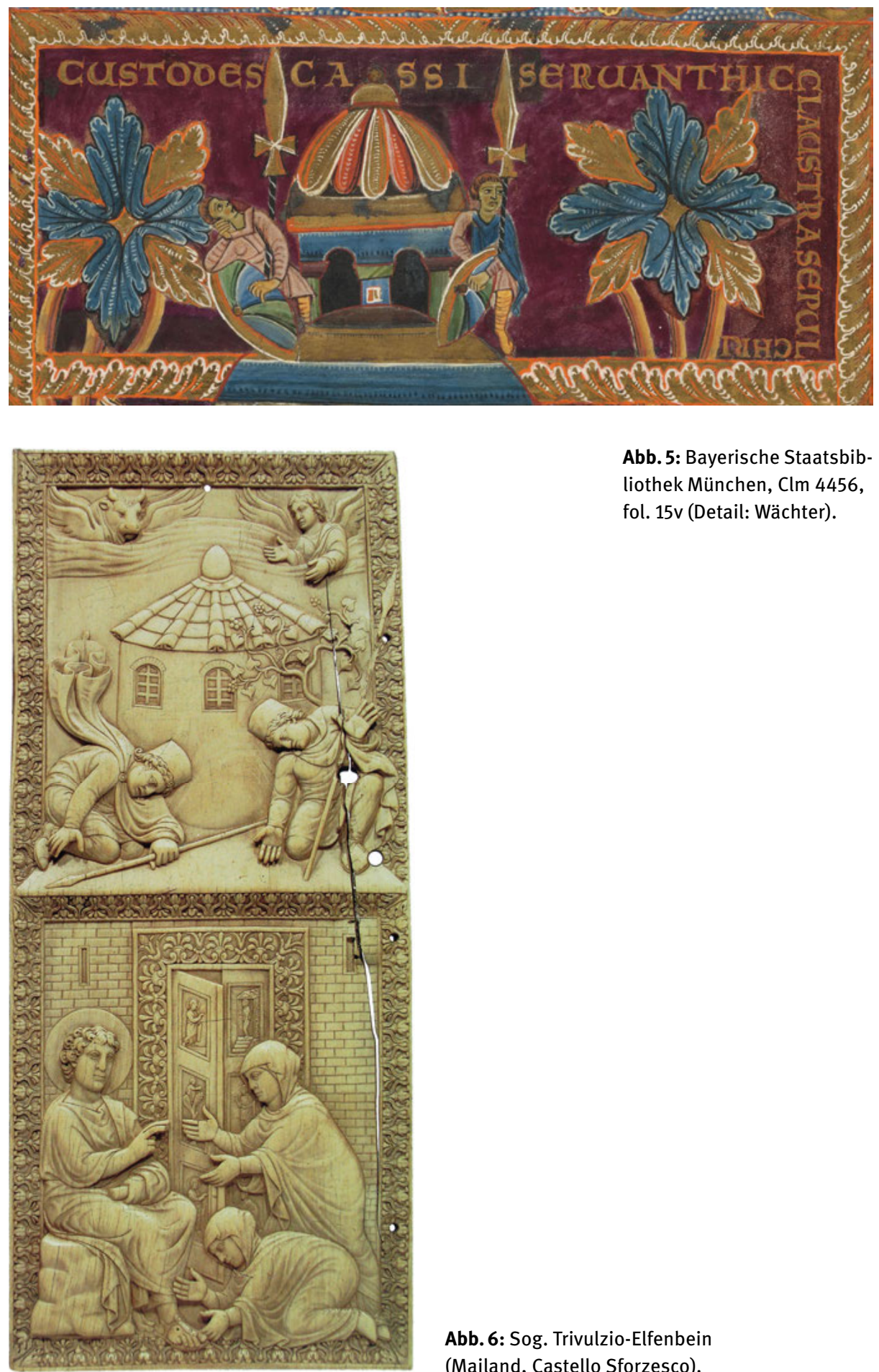

Abb. 5: Bayerische Staatsbibliothek München, Clm 4456, fol. 15v (Detail: Wächter).

Abb. 6: Sog. Trivulzio-Elfenbein (Mailand, Castello Sforzesco). 
zwischen die Lanzen platziert, und damit hervorgehoben und betont wurde. Dieses Wort, das bereits auf semantischer Ebene alles andere als eindeutig ist, lässt sich potentiell sowohl auf die Wächter (im Nominativ: custodes cassi) als auch auf das Grab (im Genitiv: cassi...sepulchri) beziehen. ${ }^{14}$ Die Inschrift spricht also in gewisser Hinsicht gleichermaßen von den „leeren Wächtern“ (im Sinne von „unnütz“, „eitel“ oder eben „taub“) wie auch von dem „leeren Grab“ - ein Wortwitz, der offensichtlich selbst den nach oben blickenden Soldaten in Erstaunen versetzt bzw. zum Grübeln bringt. Dass dieses Wort aber keinesfalls nebensächlich ist, verdeutlicht seine Platzierung direkt über der Kuppel des Grabes. Die Miniatur, die von dem monumentalen Grabbau beherrscht wird, steht gänzlich im Zeichen der „Leere“: Einerseits das untrügliche Indiz des geschehenen Wunders, andererseits der Zustand einer beunruhigenden „Absenz“ und eines spirituellen „Mangels“.

In unserem Zusammenhang ist aber insbesondere darauf hinzuweisen, dass den beiden Wächterfiguren ein genauer Ort zugewiesen wird, und zwar durch das in frühmittelalterlichen Bildtituli nicht selten gebrauchte Lokaladverb „hic“: Eben hier bewachen die Wächter (vergeblich) die Siegel des Grabes. Dabei macht die Anordnung der Inschrift, die an zwei Ecken umknickt und den Rahmen des Bildfeldes bestätigt, auf fast gestische Weise deutlich, welcher Raum diesen „unnützen“ Figuren zugestanden wird. Interessant, weil wiederum doppeldeutig, ist in diesem Kontext die Verwendung des Wortes claustra, das zunächst sicherlich die Riegel des Grabes meint, aber eben auch generell an das Eingeschlossensein, an eine Umfriedung denken lässt ${ }^{15}$ - eine Umfriedung, die von dem Palmetten-Ornament vorgenommen und von der Schrift verstärkt wird.

Auch das größere Bildfeld darunter wird von einem Titulus bestimmt. Dieser nimmt Bezug auf den Engel des Herrn, Angelus Domini, der „hier die Siegel des Grabes löst“ (hic solvit signacula busti). Im Ganzen lässt sich die deiktische Botschaft der Miniatur auf folgende Formel bringen: Hier die Wächter, die vergeblich ausharren, hier der Engel, der das Grab öffnet und gerade nicht hier: Christus der Auferstandene. Dies ist wohl die Pointe dieser Darstellung, denn die Botschaft des Engels an die Frauen beinhaltet den Evangelienberichten zufolge gerade nicht die Präsenz, sondern die Absenz Christi.

So heißt es im Markusevangelium:

Iesum quaeritis [...] non est hic. ecce locus ubi posuerunt (Mk 16,6).

(„Ihr sucht Jesus von Nazareth [...] Er ist auferweckt worden, er ist nicht hier. Seht da die Stätte, da sie ihn hingelegt hatten.")

14 Die mittellateinische Expertise plädiert für den primären Zusammenschluss der Wörter cassi... sepulchri. Wie mir Tino Licht mitteilte, ist die Übersetzung im Sinne von „leeren“ Wächtern eine nicht gerade elegante „Wörterbuchübersetzung“. Allerdings ist darauf hinzuweisen, dass nicht nur die Alliteration der unmittelbar aufeinander folgenden Wörter (custodes cassi) einen entsprechenden Zusammenhang nahelegt, sondern auch die Platzierung der Worte direkt über den Wächterfiguren. 15 Es ist auch an unzugängliche Kammern zu denken. Diesen Hinweis verdanke ich Tino Licht. 
Ähnlich lässt der Engel im Matthäusevangelium verlautbaren:

[...] non est hic. Venite videte locum ubi positus erat Dominus (Mt 28,6).

(,[...] er ist nicht hier. Kommt und seht den Ort, wo sie den Herrn hingelegt hatten.“)

Das Lokaladverb hic wird nun durch den Zeigegestus des Engels mit dem ausgestreckten Zeigefinger bildlich substituiert. Was für einen Ort, welchen locus sehen wir aber nun? Wie ist dieser qualifiziert? - Es ist zunächst ein Ort, der von Architekturelementen aus edlem Gestein begrenzt und ausgezeichnet wird (Abb.7): Links und rechts grün gesprenkelte Marmorsäulen bzw. Rundpfeiler; darüber ein blauer, mit weißlichen Querstreifen durchzogener Steinbogen. ${ }^{16}$ Darin ist nun - vor dem Purpurgrund deutlich abgehoben - das strahlend weiße Leinentuch erkennbar, mit dem der Leichnam Christi eingewickelt war und darüber das Schweißtuch (sudarium), das dem Johannesevangelium zufolge „nicht bei dem Leinentuch (linteamina) [lag], sondern für sich zusammengefaltet an einer besonderen Stelle“ (Joh 20,6f.). ${ }^{17}$

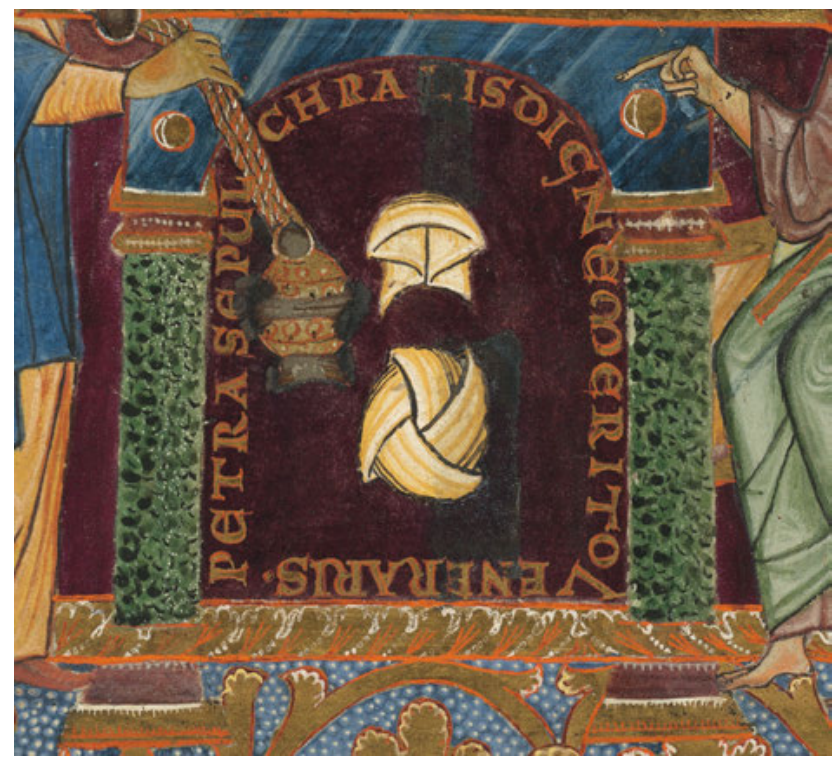

Abb.7: Bayerische Staatsbibliothek München, Clm 4456, fol. 15v (Detail: Grabkammer).

\footnotetext{
16 Nicht nachvollziehbar ist an dieser Stelle die Beschreibung von Pippal 2010b, 110, die in der Grabkammer einen rechteckigen Sarkophagdeckel ausmacht, auf dem die Leichentücher liegen sollen. Es kann sich bei diesem angeblichen ,Deckel' nur um die (durch die Oxidation des Silbers sichtbare) Kontur des Kreuzstammes von der Vorderseite des Blattes handeln. Der einzige Sarkophagdeckel ist außerhalb des Grabes zu sehen. Er fungiert als Sitzfläche des Engels.

17 Als der mit Petrus herbeigeeilte (nicht namentlich genannte) Jünger dies sah, so bei Johannes weiter, „sah und glaubte er“ (et vidit et credit) - dies, obwohl sie, die Apostel, „,noch nicht die Schrift kannten“ (nondum enim sciebant scripturam). Joh 20,6f.
} 
Erstaunlicherweise bezieht sich nun die Inschrift im Inneren nicht auf diese Textilien (die als Berührungsreliquien ja durchaus verehrungswürdig wären), sondern direkt auf den Grabbau bzw. den „Grabstein“ selbst. So ist von links unten im Uhrzeigersinn zu lesen:

\section{PETRA SEPULCHRALIS DIGNE MERITO UENERARIS}

(„Grabstein, Du wirst würdig zu Recht verehrt.“) $)^{18}$

Die Sonderstellung dieser Inschrift innerhalb der Miniatur ist evident: Nicht die Handlung eines menschlichen oder göttlichen Akteurs wird hier schriftlich bezeichnet. Vielmehr wird ein Artefakt, die petra sepulchralis, direkt in der zweiten Person Singular angesprochen, der (so die wörtliche Übersetzung) „Grabstein“ selbst. An dieser Stelle kommt nun explizit das sakrale Element ins Spiel. Es geht ausdrücklich um Verehrung, veneratio, und zwar um eine liturgisch ritualisierte Verehrung darauf verweist das Weihrauchfass, das die vordere Maria schwenkt. Dabei erinnert die Wendung digne merito wohl nicht zufällig an den Anfang des Messkanons, der mit den Worten anhebt: „In Wahrheit ist es würdig und recht ...“ (Vere dignum et iustum est). Die Verehrung gilt in diesem Fall nun aber nicht der Maiestas des Herrn, sondern einem Stein, eben der petra sepulchralis. Es kann kein Zweifel bestehen, dass damit das gesamte Grabmonument gemeint ist: In der biblischen Vulgata wird das Felsengrab als monumentum excisum de petra $(\mathrm{Mk} 15,46)$ bezeichnet; der Stein, mit dem der Zugang versperrt war, dagegen als lapis oder saxum. ${ }^{19}$ An das ganze Grabmonument ist also die schriftlich festgehaltene Rede der Marien adressiert. Mit diesem Wissen wird erst die monumentale, schier riesenhafte Erscheinung des Mausoleums verständlich, das eine phantastisch anmutende Kuppelarchitektur aufweist und mit seiner Vielzahl an Geschossen, Fensteröffnungen, Arkaden und bunten Horizontalstreifen in die Höhe wächst und die Binnengliederung des Bildfeldes zu sprengen vermag. ${ }^{20}$ Jetzt erst werden auch die spezifischen Blickrichtungen der Wächter ganz oben lesbar: Trotz ihrer körperlichen Nähe zum verehrungswürdigen Grabbau scheinen sie diesen gar nicht zu bemerken. Im Gegenteil: Indem sich beide davon abwenden und demonstrativ davon wegschauen, wird ihr Mangel an Devotion und Ehrerbietung offenbar.

Der innerste Bereich, der „Ort“ oder die „Stätte“ (locus), „wo sie den Herrn hingelegt hatten“ wird nun zweifelsohne als der Mittelpunkt der Heiligkeit in Szene gesetzt - wobei der spezifischen Anordnung der goldenen Unzialschrift eine wichtige

18 Kaiser Heinrich II. 1002-1024 2002, 272 und die geringfügig abweichende Übersetzung bei Pippal 2010b, 110, die allerdings gerade das wichtige Anfangswort petra unterschlägt: „Heiliges Grab, Du wirst würdig zu Recht verehrt.“

19 Mt 27,60: „ein Grab, das er in den Felsen hatte hauen lassen. Da wälzte er einen großen Stein vor den Eingang“ (monumento suo novo quod exciderat in petra et advolvit saxum magnum ...); Mk 15,46: „legte ihn in ein in den Felsen gehauenes Grab und wälzte einen Stein vor den Eingang des Grabes“ (posuit in monumento quod erat excisum de petra et advolvit lapidem ad ostium monumenti).

20 Vgl. Pippal 2010b, 110f. 
Rolle zukommt, umschließt sie doch vollständig die Bogenstellung der Graböffnung, die so gleichsam durch eine Buchstabenkette geschützt und gesichert wird. Weder der Engel, noch die Frauen dringen in diesen Bereich ein. In gebührendem, respektvollem Abstand stehen sie neben diesem heiligen und schriftgesicherten locus. Nur das Weihrauchgefäß vermag es, die Buchstabenfolge aufzubrechen. Ob Zufall oder nicht: Ausgerechnet das Wort sepulchralis wird durch dieses liturgische Gefäß getrennt: SEPUL/CHRALIS. In metaphorischer und zugleich sehr anschaulicher Weise wird hier das Lösen der Siegel selbst gezeigt, über deren Unversehrtheit die römischen Soldaten vergeblich wachen.

Dabei erinnere man sich nochmals an den Begriff claustra, mit dem die „Riegel“ des Grabes gemeint waren und der, wie erwähnt, an eine Umfriedung denken lässt. Die Schrift selbst scheint nun diese Funktion zu erfüllen; die Buchstaben, so hat man den Eindruck, fungieren als claustra des Grabes, grenzen ab, verschließen, sind auch selbst verschlossen und werden erst durch eine liturgische actio geöffnet: Hier die Beweihräucherung (incensatio) durch die vorderste Maria, die das Grab wie einen Altar zu Beginn der Messe inzensiert. ${ }^{21}$

Diese Analogie zwischen Altar und Grab ist für die christliche Liturgieallegorese nun völlig geläufig und besonders in diesem Fall nicht abwegig, berücksichtigt man den spezifischen Ort der Miniatur innerhalb der Handschrift und wiederum deren besondere Funktion. Wie anfangs erwähnt, handelt es sich bei der von Heinrich II. gestifteten Prachthandschrift um ein Sakramentar, das die priesterlichen Formeln für die Messe beinhaltet. Die Miniatur mit dem Ostergrab ist genau vor dem Beginn des Messkanons platziert, der mit den Anfangsworten „Te igitur“ anhebt und später in den eucharistischen Wandlungsworten seinen Höhepunkt findet: Der auferstandene, aber abwesende Leib Christi wird nun mit Kelch und Hostie der Gemeinde wieder rituell präsent gemacht, wird in seiner Realpräsenz gefeiert.

Die große T-Initiale des „Te igitur“, aus dessen Stamm goldene Ranken sprießen, symbolisiert das Kreuz Christi, das nicht den endgültigen Tod bedeutet, sondern im Gegenteil das ewige Leben bringt (Abb.4). Der Buchstabe T, mit dem der Messkanon beginnt, wurde von mittelalterlichen Liturgikern aber nicht nur als Heilszeichen gedeutet, sondern im Sinne des Alten Testaments auch als Schutzzeichen. ${ }^{22}$ Im Buch Exodus wird davon berichtet, dass Gott den Israeliten befahl, am Pascha-Fest die „Türpfosten und die Oberschwelle“ (Ex 12,7) mit dem Blut eines Lammes zu bestreichen, um von der letzten der ägyptischen Plagen verschont zu bleiben. Christliche Theologen des Mittelalters verstanden dies so, dass die Türschwellen von den Israeli-

21 In diesem Sinne lassen sich auch die Tücher im Inneren als liturgische Paramente verstehen. Der Liturgieallegorese des Amalarius von Metz zufolge verweist das große Altartuch, das Corporale, auf das Leinentuch, in das der Leib Christi gewickelt war, während das kleine Altartuch, mit dem der Kelch gehalten wird, das Sudarium, bezeichnet. Amalarius, Liber Officialis III, 26. Ed. Hanssens 1948-1950, Bd.2, 346.

22 Vgl. Suntrup 1980, 293; Schreiner 2000, 69f.; Dinkler 1962, 97. 
ten mit dem Zeichen des Kreuzes versehen wurden. Dieses signaculum crucis konnte wiederum mit dem hebräischen Tav oder griechischen Tau (gem. Ez 9,4) in Verbindung gebracht werden. Als Illustration sei auf eine Emailtafel eines Kreuzes aus dem 12. Jahrhundert verwiesen, die Aaron, den Bruder des Moses, zeigt, der den Giebel eines Gebäudes mit einem großen T-Buchstaben markiert (Abb. 8).

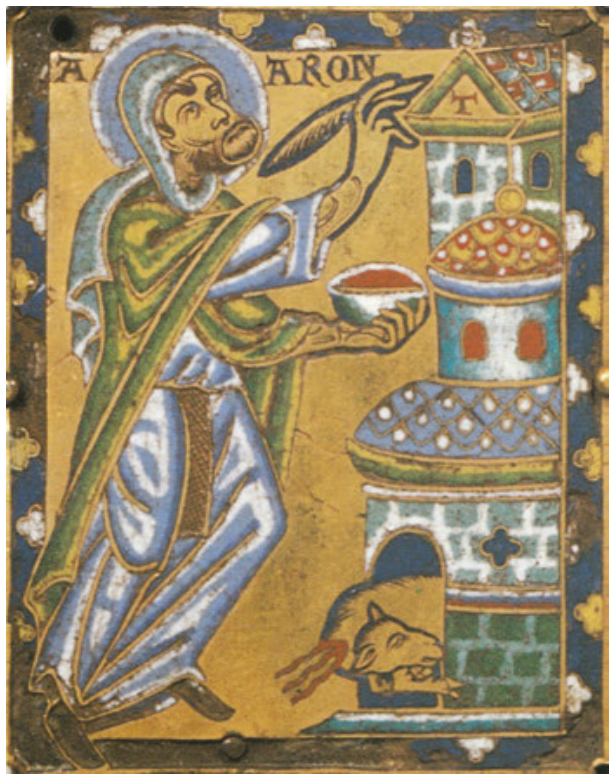

Abb. 8: Kruzifix, Detail: Aaron zeichnet mit dem Blut des Lammes den Buchstaben T auf den Giebel eines Hauses (vgl. Ex 12,7-13). 12. Jahrhundert, Grubenschmelz. London, Victoria and Albert Museum, Inv.-Nr. 7234.

Die christliche Exegese beschäftigte sich seit ihren Anfängen mit diesem mystischen Tav, das als letzter Buchstabe des hebräischen Alphabets als Zeichen der Vollkommenheit verstanden wurde und als erster Buchstabe des Wortes „Thora“ die Summe des göttlichen Gesetzes symbolisierte. ${ }^{23}$ Folgt man dem Exodus-Bericht selbst, war der Blutanstrich aber, wie gesagt, primär als Raum-Schutz und Grenz-Markierung bedeutsam.

Welcher Raum wäre das nun im Falle des Regensburger Sakramentars? Es ist, so meine These, der Schriftraum des Messkanons, den allein der Priester zu beschreiten hat. Dass diese Interpretation keinesfalls zu gewagt ist, mag ein Vergleich mit zeitgenössischen Messordines belegen. So wird im Ordo romanus der Übergang von der Präfation zum Opfergebet - vom Jubelgesang des Sanctus zum stillen Opfergebet - mit den Worten kommentiert: „Es erhebt sich allein der Bischof und betritt stillschweigend den Kanon“ (Surgit solus pontifex et tacito intrat canonem). ${ }^{24}$

23 Vgl. Suntrup 1980, 290f.; Schreiner 2000, 69-72.

24 Ordo secundum Romanos (Ordo V). Andrieu 1948, Bd.2, 209-227. Seit dem 8. Jahrhundert war es üblich, dass nach dem laut gesungenen Sanctus kurz vor dem Kanon allgemeine Stille einkehrte. Die 
Ganz offensichtlich wird der Messkanon hier als eine Art virtueller Raum verstanden, in den - wenn auch metaphorisch - der Zelebrant alleine zu schreiten hat (intrat). In diesem Sinne lässt sich die T-Initiale im Sakramentar als signum verstehen, das erstens die Aufgabe hat, den Schriftraum des Messkanons als exklusiven Heilsraum zu kennzeichnen und zweitens als Grenzmarkierung fungiert, die vor unbefugtem Zugang zu warnen hat. Dies wird auch durch die spezifische materielle Gestaltung der Initialzierseite nahe gelegt, die in ihrem ornamentalen Reichtum ja nicht lesbar im eigentlichen Sinne ist, sondern den Blick vielmehr auf sich zieht, diesen Blick bindet und auch fordert - lassen doch die Goldranken, die über die Majuskel-Buchstaben ausgebreitet sind, diese wie hinter einem metallenen Sperrgitter verschwinden. ${ }^{25}$ Dieser Effekt tritt noch deutlicher zutage, bedenkt man die originalen Rezeptionsbedingungen der Zeit vor 1000 Jahren, die wenig mit der gleichmäßigen Ausleuchtung einer „Grazer Buchwiege“ zu tun hatten (Abb.9), sondern von den changierenden Lichteffekten des Kerzenlichtes bestimmt wurden. Unter diesen Bedingungen dominierte der metallische Glanz des Blattgoldes den ästhetischen Eindruck (Abb.10).

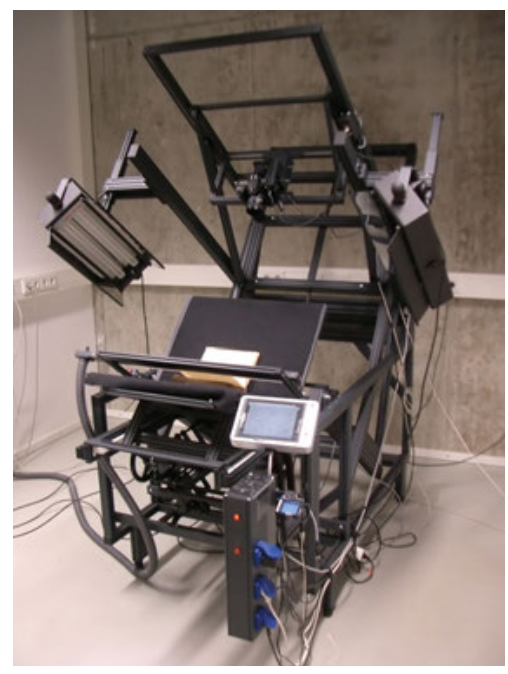

Abb. 9: Grazer Buchtisch. Standort: Digitalisierungszentrum der SLUB Dresden.

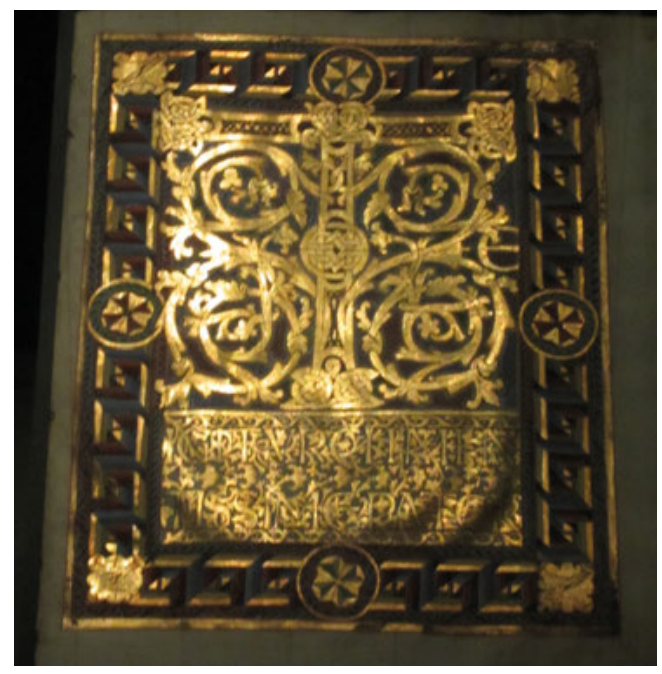

Abb. 10: Bayerische Staatsbibliothek München, Clm 4456, fol. 16r.

Während die große T-Initiale dadurch sicherlich noch mehr an Präsenz gewann, verschwanden die folgenden Worte unter dem flächendeckenden Rapport des Rankenornaments, das sich vor die Buchstaben wie ein undurchdringliches Metallgitter legte.

Gemeinde hatte nun zu verstummen und sich zu verbeugen, das anschließende Opfergebet wurde allein vom Priester mit gedämpfter Stimme rezitiert. Vgl. Jungmann 1962, Bd. 2, $174 \mathrm{f}$.

25 Vgl. hierzu auch Frese 2014, 4f. 


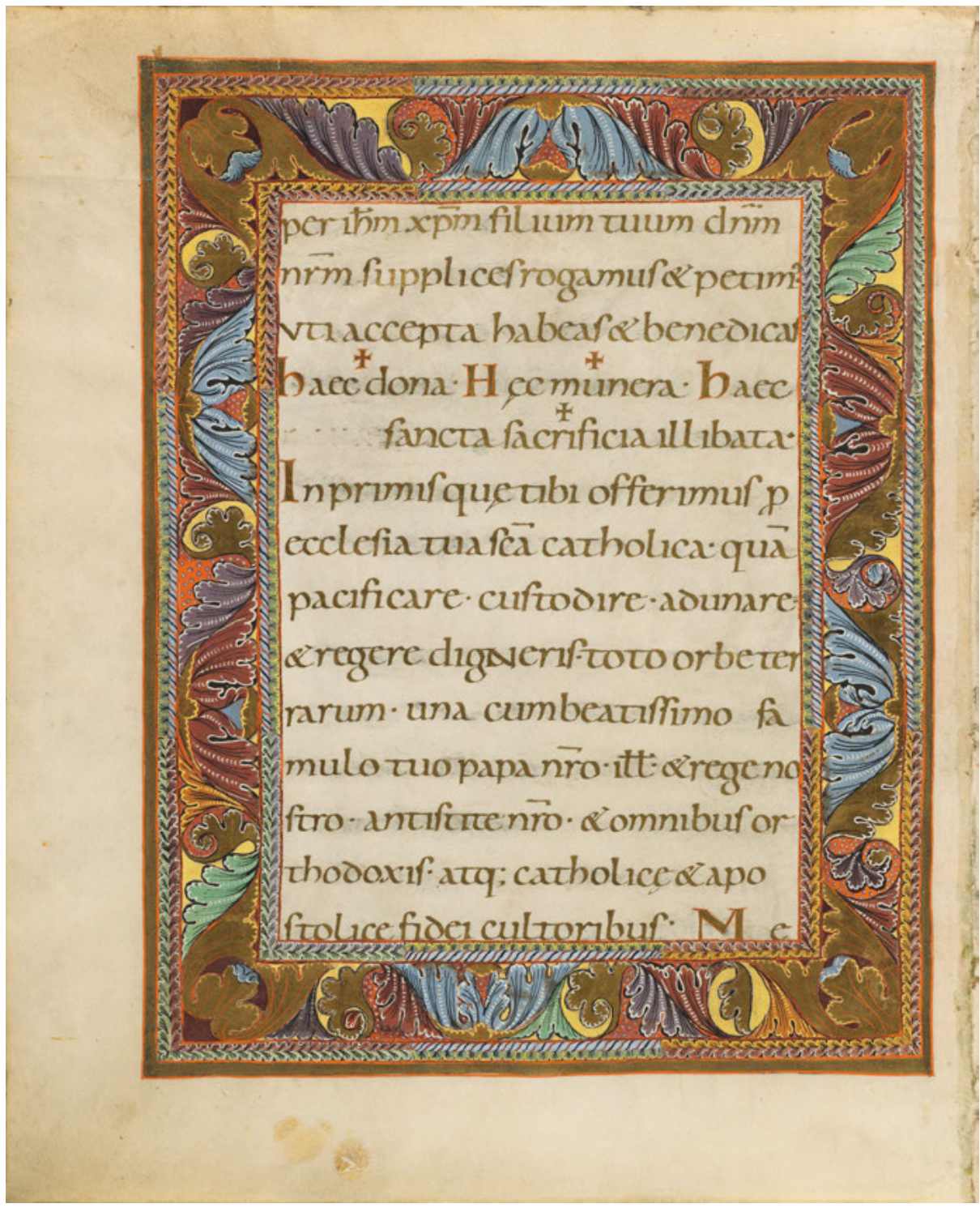

Abb. 11 (beide Seiten): Bayerische Staatsbibliothek München, Clm 4456, fol. 16v-17r.

Blätterte der Diakon für den zelebrierenden Priester nun weiter, hatte er den Text des Opfergebets in größter Klarheit und bester Lesbarkeit vor Augen (fol.16v-17r, Abb. 11). Auf blankem Pergament mit Goldtinte geschrieben und in großzügigem Zeilenabstand angeordnet, präsentierte sich ihm der Kanon in Unzialbuchstaben. Umrahmt 


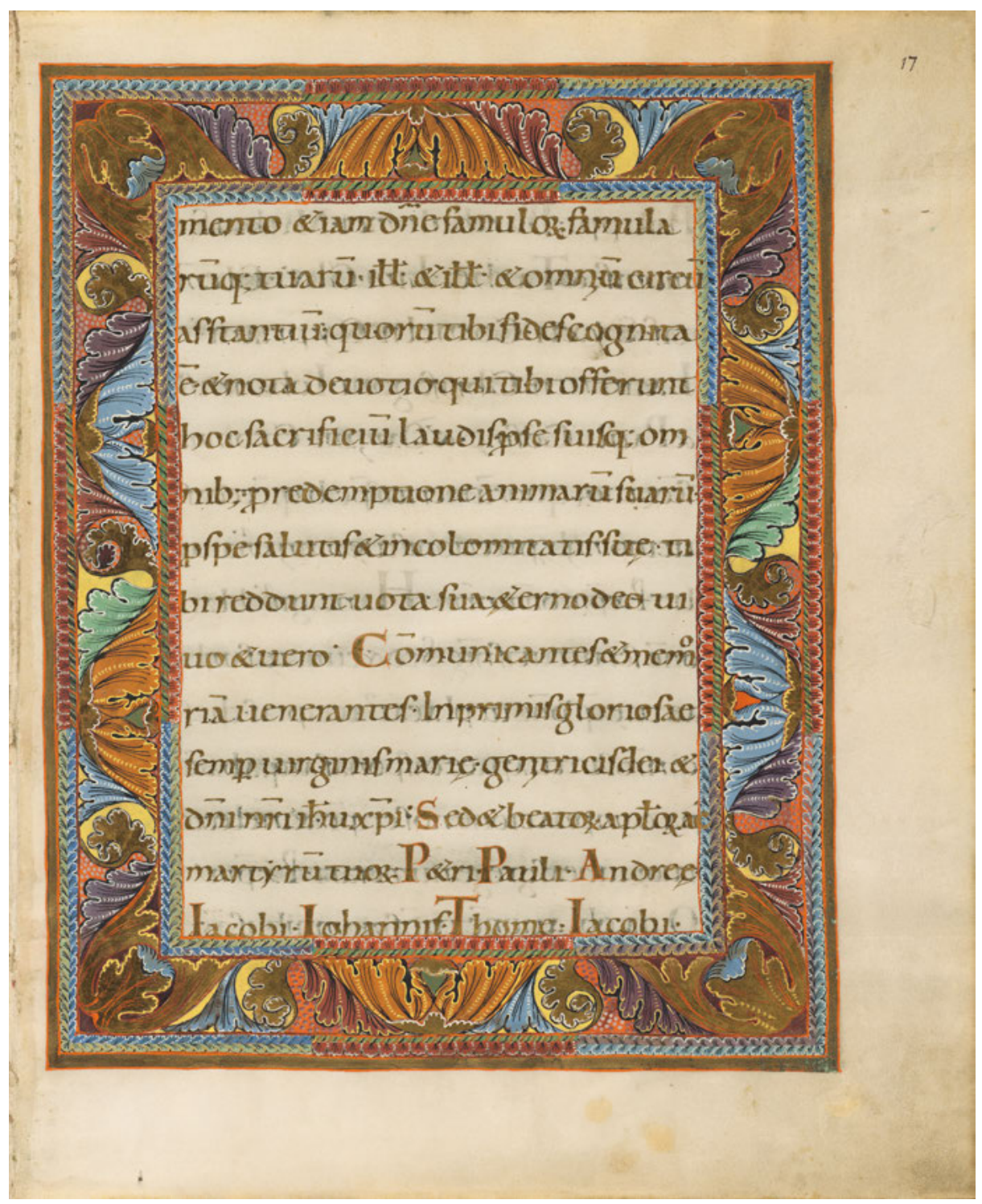

von einer breiten Bordüre mit buntem, üppigem Rankenwerk wurde ihm dieser Text zudem wie in einem Tableau präsentiert. Dabei wurde offensichtlich darauf geachtet, den ornamentalen Zusammenschluss der beiden gegenüberliegenden Seiten zu einem Doppeltableau zu wahren: So fällt auf, dass die Form der großen Blattmo- 


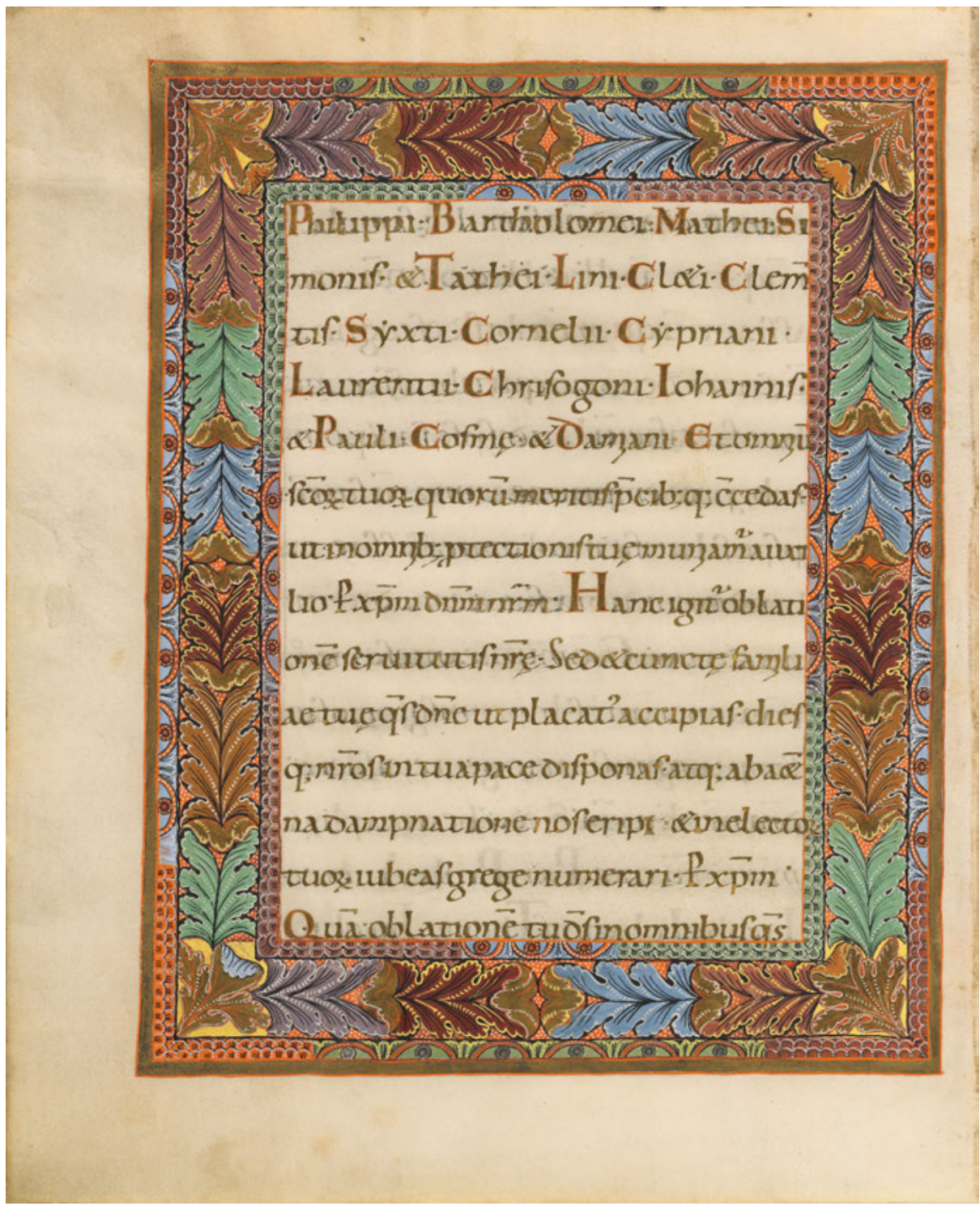

Abb. 12 (beide Seiten): Bayerische Staatsbibliothek München, Clm 4456, fol. 17v-18r.

tive ziemlich genau übereinstimmt und nur in der Kolorierung variiert. ${ }^{26}$ Dies muss umso mehr auffallen, als dies für die direkt darauffolgende Doppelseite wiederum nicht zutrifft (Abb.12). Hier sind links (fol.17v) achtlappige Blätter in recht akkuratem

26 Diese ornamentale Angleichung bestimmt auch die prächtigen Doppelblätter im Kalenderteil des Sakramentars (fol.5v-10r). 


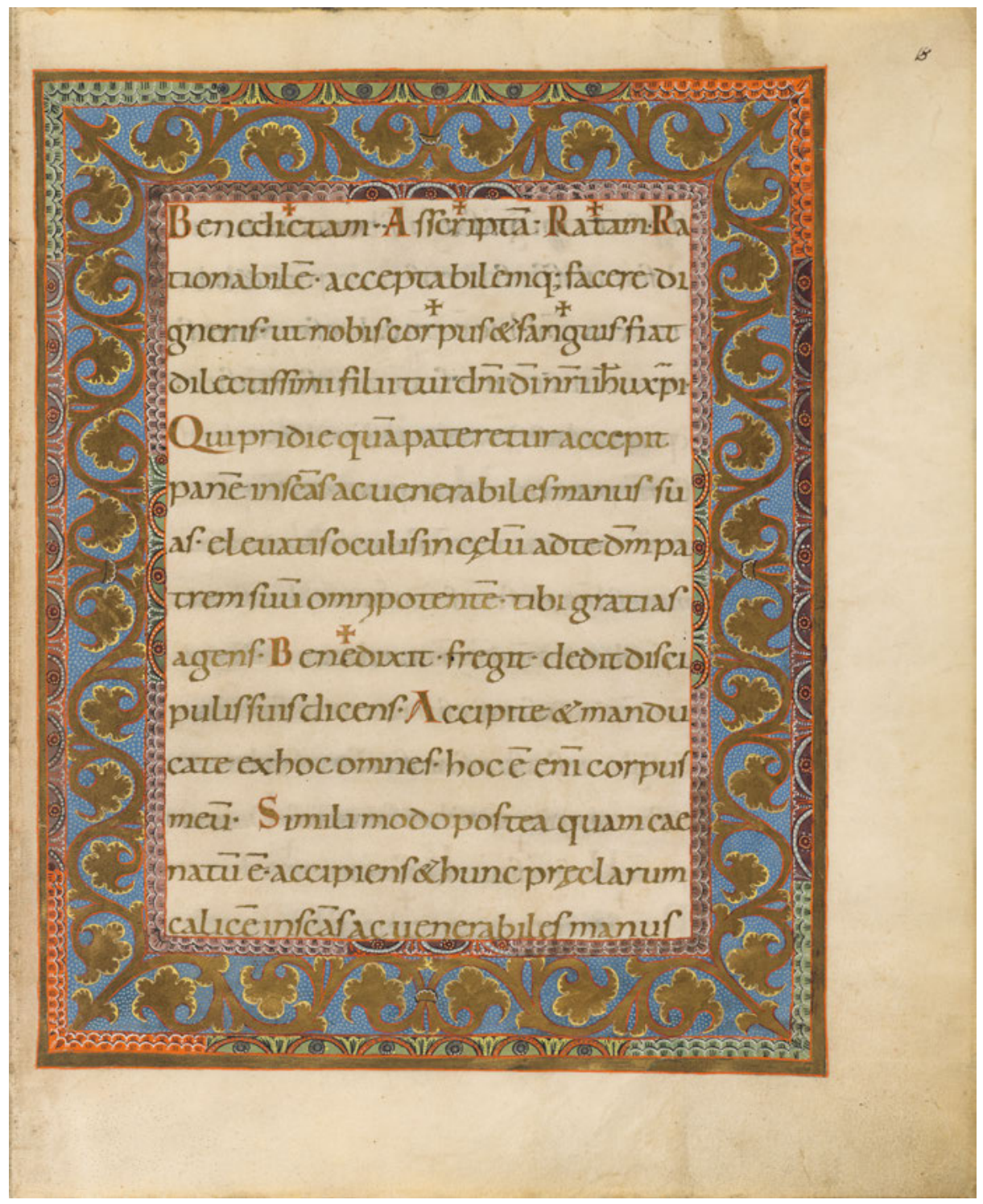

Rapport angeordnet, rechts (fol.18r) dagegen wellenförmig schwingende Goldranken vor blauen Grund. ${ }^{27}$ Beim aufmerksamen Rezipienten, der nicht nur den Text liest,

27 Interessant ist allerdings, dass die schmalen Bänder, die die breiten Mittelbänder rahmen, motivisch übereinstimmen, sodass der Zusammenschluss der gegenüberliegenden Seiten - wenn auch auf subtile Weise - gewahrt bleibt. Vgl. Pippal 2010b, 116. 


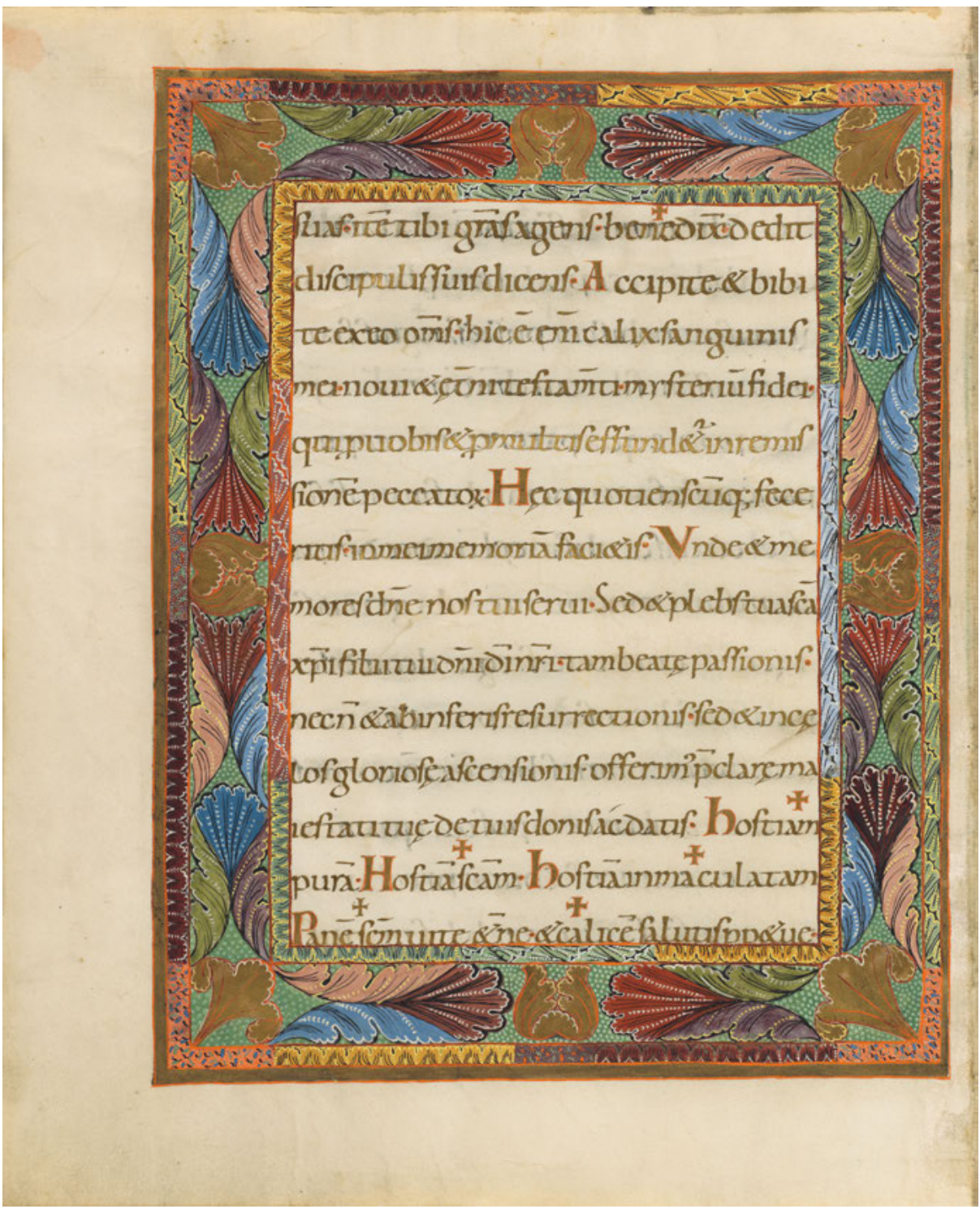

Abb.13 (beide Seiten): Bayerische Staatsbibliothek München, Clm 4456, fol. 18v-19r.

sondern auch auf den spezifischen Einsatz des Ornaments achtet, stellt sich an dieser Stelle ein überraschender Déjà-vu-Effekt ein. Und richtig: Genau diese Goldranken auf blauem Grund waren bereits auf der Seite mit dem Heiligen Grab zu sehen (fol. 15v) ${ }^{28}$ Was ist aber auf dieser derart gleichartig ausgezeichneten Textseite $\mathrm{zu}$ lesen? Es ist

28 Vgl. Pippal 2010b, 57, 110, 116. 


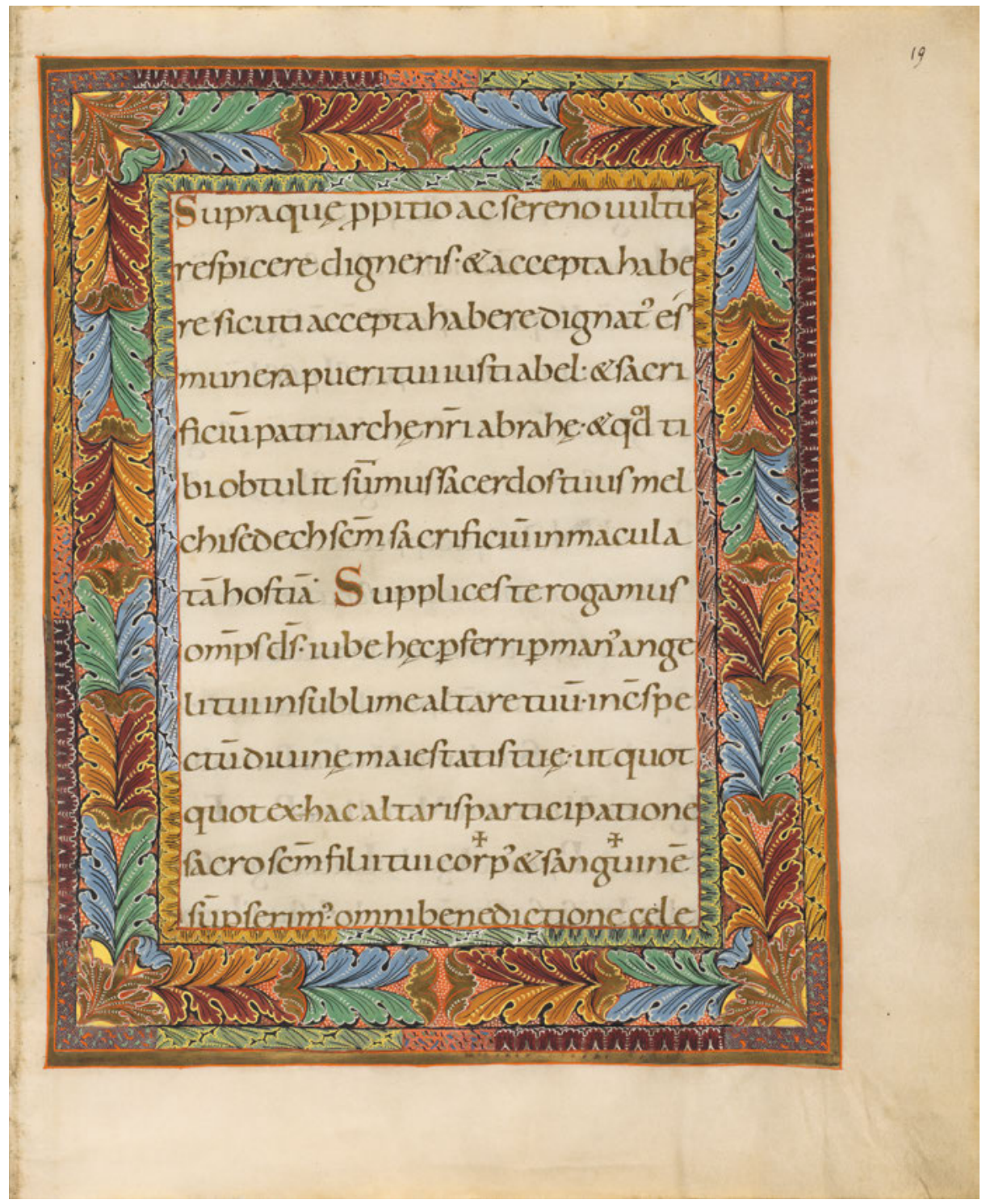

wohl nicht zufällig der mit einer Vielzahl an Benediktionskreuzen versehene Text, der den Höhepunkt des Messkanons beinhaltet - kulminierend in den Wandlungsworten: „Dies ist nämlich mein Leib“ (Hoc est enim corpus meum). Die Fortsetzung des Wandlungsgeschehens folgt auf der nächsten Seite (fol.18v, Abb.13). Hier nun wird auch der „Kelch des Blutes“ (Hic est enim calix sanguinis) aufgerufen und entsprechend vom Priester gesegnet. Umrahmt wird der Text von langestreckten, schräg 
angeordneten Blattformen zwischen Goldknospen, wie sie ein zweites Mal nur auf der Kreuzigungsseite zu sehen sind (fol.15r). ${ }^{29}$ Durch diese ornamentale Einkleidung stellt sich das Textblatt 18 in seinen beiden Seiten (recto und verso) gewissermaßen als umgekehrte ,Reprise' der Bilderfolge auf fol.15 dar, wobei die Kreuzesminiatur (fol.15r) mit dem „Kelch des Blutes“, das Bild des Ostergrabes (fol.15v) mit dem Leib Christi verlinkt wird. In einer raffinierten Referenzstruktur werden die beiden Kanonbilder mit dem späteren Einsetzungsbericht verbunden und damit im engsten Sinne als eucharistische Bilder ausgewiesen - ein in der Illustration des Messkanons einmaliger Fall. ${ }^{30}$ Berücksichtigt man die kodikologische Expertise, so stellt sich heraus, dass die beiden Blätter 15 und 18 sogar direkt physisch miteinander verbunden sind: In der Analyse des Lagenaufbaus erweisen sie sich als die beiden Hälften eines Doppelblattes. ${ }^{31}$ Das Ornament verdeutlicht und verstärkt diese für den Benutzer des Buches kaum sichtbare, aber sehr materielle Verbindung.

Das heißt wiederum: Der Raum des Opfergebets wird zwar durch das Signum der Te igitur-Initiale eingeleitet und geschützt, steht aber mit den beiden vorgeschalteten Kanonbildern in unmittelbarer Verbindung. Der Schriftraum wird hier gleichsam ,mitgesehen' und proleptisch eröffnet. In diesem Sinne steht auch das einzigartige Osterbild bereits im Zeichen erfüllter Gegenwart. Schließlich wird das Non est hic des Engels am Grabe virtuell vom Herrenwort Hoc est corpus meum sekundiert. Derart sensibilisiert fällt auf, dass das von den Lanzen ausgesparte und isoliert hervorgehobene Wort CASSI von der Spitze der Grabkuppel durchstoßen wird (Abb. 5). Im direkt anschaulichen Sinne wird die „Leere“ von dem hoch aufragenden Felsengrab selbst durchbrochen. Das phantastisch anmutende Mausoleum füllt mit seiner Präsenz gleichsam das Vakuum. Es erscheint nicht allzu kühn, diese verehrungswürdige petra sepulchralis mit dem Leib des auferstandenen Christus selbst zu identifizieren. Der Blick auf ein nur wenige Jahrzehnte jüngeres Artefakt mag diese Deutung stützen: Im Regensburger Benediktinerkloster St. Emmeram befindet sich in der Mitte des Doppelportals ein Relief aus Kalkstein, das in der Zeit um 1060 hergestellt wurde und den

29 Vgl. Pippal 2010b, 116f.

30 Tatsächlich ist es bemerkenswert, dass in frühmittelalterlichen Sakramentaren die Wandlungsworte des Messkanons selbst niemals direkt illustriert wurden. Schon Elbern stellte fest: „Es ist sehr merkwürdig, dass der Messkanon, der wichtigste Teil der Liturgie und der Kern des Sakramentars, im frühen Mittelalter keine weitere bildliche Ausschmückung erfahren hat. Hätte es nicht nahegelegen, beispielweise die in der ,Wandlung' der Messe wiederholte Einsetzung der Eucharistie mit einer entsprechenden Darstellung des ,Letzten Abendmahls‘ oder der ,Apostelkommunion` zu begleiten? [...] Ist es fromme Scheu, die das eigentliche Mysterium des christlichen Kultes ganz ohne Bild belässt, es vielmehr dem ,Worte‘ allein vorbehält?“ Elbern 1965, 61.

31 Dieses Doppelblatt wurde zunächst aus zwei Einzelblättern zusammengefügt und dann in die dritte Lage des Codex (fol.12-21), einem Quinternio aus fünf Doppelblättern, integriert. Vgl. Klemm 2004, 32; Gullath 2010, 11. 
thronenden Christus mit Buch und Segensgestus zeigt (Abb. 14). ${ }^{32}$ Umschlossen wird diese Figur von folgender Schrift in Kapitalbuchstaben:

CUM PETRA SIT DICTUS STABILI P[ro] NUMINE / XPC ILLIVS / IN SAXO SATIS APTE CONSTAT IMAGO

(„Weil Christus wegen seiner unerschütterlichen Göttlichkeit Fels [petra] genannt wird, besteht dieses sein Bild ganz zu Recht aus Stein [saxo]")

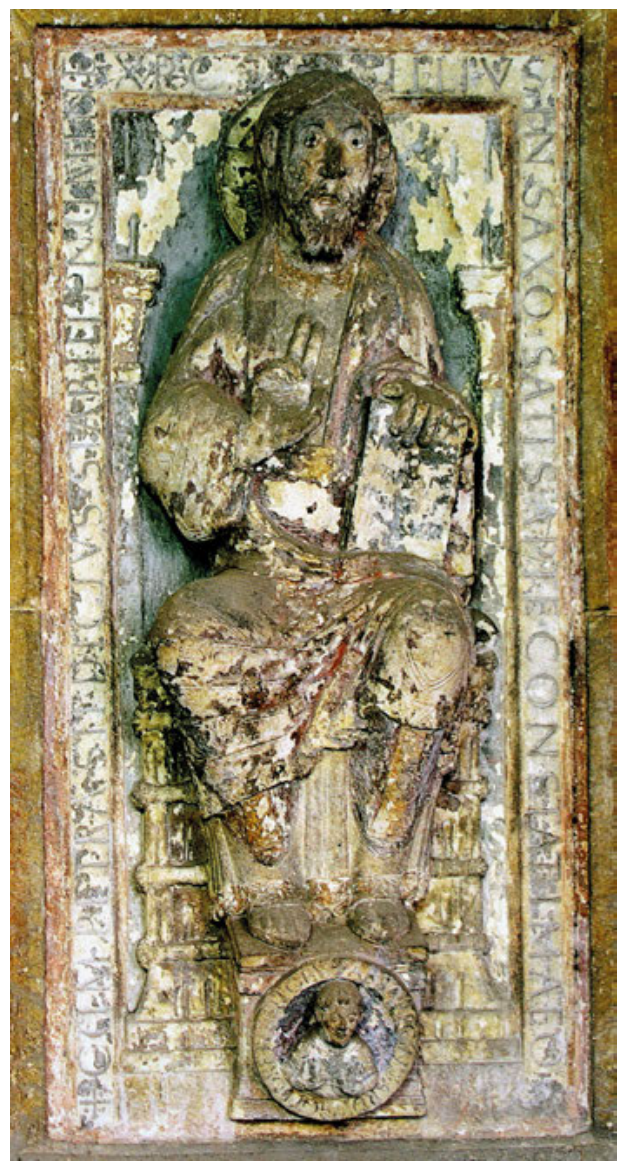

Abb.14: Salvator-Relief. Regensburg, St. Emmeram.

32 Vgl. Wittekind 2009, Kat.-Nr. 67 (Heidrun Stein-Kecks) und Kat.-Nr.186 (Matthias Untermann). Das Relief wurde der Stifterinschrift zufolge in den Jahren der Regierungszeit des Abtes Reginward (1048-1064) angefertigt. Vgl. Raff 2008, 57. 
Bemerkenswert an dieser lange Zeit ignorierten Inschrift ist nicht nur, dass explizit die Steinqualität des Artefakts thematisiert wird. ${ }^{33}$ In unserem Zusammenhang noch interessanter ist, dass das Wort petra in größtmöglicher Deutlichkeit als eine Bezeichnung für Christus herausgestellt wird - eine Bezeichnung, die für dessen ,unerschütterliche Göttlichkeit“ (stabili pro numine) stehen soll und mit Sicherheit auch im eucharistischen Sinne zu verstehen ist. ${ }^{34}$

Im Sakramentar Heinrichs II. - eine Handschrift, die wohlgemerkt in St. Emmeram hergestellt wurde - scheint dieser semantische Bezug bereits bekannt $\mathrm{zu}$ sein und für das Verständnis der Miniatur auf fol.15v vorausgesetzt zu werden: Christus, der Fels, wird hier „würdig“ und „zu Recht“ im Bild des Mausoleums verehrt. Der locus, auf den der Engel des Herrn hinweist, mag zwar „leer“ sein; die Miniatur zeugt aber in ihrer Gesamtheit von der Gegenwart Gottes, konkreter: der sakramentalen Präsenz Christi. Die schiere Größe des alles überragenden Felsengrabes führt vor Augen, dass diese Präsenz von potentiell ubiquitärem Charakter ist: Sie allein vermag es, Grenzen zu sprengen und geschiedene Binnenräume miteinander zu verbinden. Der kalkulierte Einsatz von Ornament und Schrift verdeutlicht aber, dass die spezifischen Grenzen zwischen Innen und Außen, dem Heiligen und dem Profanen, dennoch bestehen bleiben. Nicht zuletzt ist die Prominenz des Christusgrabes selbst der beste Beweis dafür, dass das Numinose an konkrete, als sakral ausgewiesene Orte, Monumente und Materialien gebunden bleibt. Venite videte locum ...

33 Vgl. Raff 2008, $57 \mathrm{f}$.

34 Die Vokabeln petra und saxum auf dem Salvator-Relief rekurrieren auf die in St. Emmeram geläufige Exegese von Deut 32,13f. im sakramentalen Sinne. Dies konnte Michele Vescovi nachweisen. Ich beziehe mich auf seinen Vortrag „Words, Images, Memory. St. Dionysius in Regensburg“ (18. Mai 2017; Heidelberg, IEK). Vgl. auch das Interview mit Nele Schneidereit: https://sfb933.hypotheses.org/tag/ relics (Stand April 2018). 


\section{Literaturverzeichnis}

Andrieu, Michel (Hg.) (1948), Les ordines romani du haut moyen age, Bd. 2 (Spicilegium Sacrum Lovaniense 24), Paris.

Brenk, Beat (2011), „Das Trivulzio-Elfenbein und seine antiarianische Mission“, in: Tobias Frese und Annette Hoffmann (Hgg.), Habitus. Norm und Transgression in Bild und Text (Festschrift für Lieselotte E. Saurma), Berlin, 245-257.

Dem Himmel entgegen (2012), Dem Himmel entgegen - 1000 Jahre Kaiserdom Bamberg 1012-2012 (Katalog zur Sonderausstellung des Diözesanmuseums Bamberg, 2002), hg. von Norbert Jung und Wolfgang F. Reddig, Petersberg.

Dinkler, Erich (1962), „Kreuzzeichen und Kreuz. Tav, Chi und Stauros“, in: Jahrbuch für Antike und Christentum 5, 93-112.

Elbern, Victor H. (1965), „Über die Illustration des Messkanons im frühen Mittelalter“, in: Peter Bloch und Joseph Hoster (Hgg.), Miscelanea pro Arte (Festschrift für Hermann Schnitzler), Düsseldorf, 60-67.

Frese, Tobias (2010), „Die Maiestas Domini als Bild eucharistischer Gegenwart“, in: Rebecca Müller und Martin Büchsel (Hgg.), Intellektualisierung und Mystifizierung mittelalterlicher Kunst. „Kultbild“: Revision eines Begriffs, Berlin, 41-61.

Frese, Tobias (2013), Aktual- und Realpräsenz. Das eucharistische Christusbild von der Spätantike bis ins Mittelalter (Neue Frankfurter Forschungen zur Kunst 13), Berlin.

Frese, Tobias (2014), „,Denn der Buchstabe tötet‘. Reflexionen zur Schriftpräsenz aus mediävistischer Perspektive“, in: Tobias Frese, Wilfried E. Keil und Kristina Krüger (Hgg.), Verborgen, unsichtbar, unlesbar. Zur Problematik restringierter Schriftpräsenz, Berlin / Boston, 1-15.

Ganz, David (2015), Buch-Gewänder. Prachteinbände im Mittelalter, Berlin 2015.

Garrison, Eliza (2012), Ottonian imperial art and portraiture. The artistic patronage of Otto III and Henry II, Farnham.

Gullath, Brigitte (2010), „Kodikologie und Geschichte des Sakramentars Heinrichs II.“, in: Sakramentar Heinrichs II. Handschrift Clm 4456 der Bayerischen Staatsbibliothek München (Kommentarband mit Beiträgen von Rolf Griebel u. a.), Gütersloh, 9-27.

Hanssens, loannes M. (Hg.) (1948-1950), Amalarii episcopi opera liturgica omnia, Bd.1-3, Città del Vaticano.

Jungmann, Josef Andreas $\left(1962^{5}\right)$, Missarum Sollemnia. Eine genetische Erklärung der römischen Messe, 2 Bde., Wien.

Kaiser Heinrich II. 1002-1024 (2002), Kaiser Heinrich II. 1002-1024 (Begleitband zur Bayerischen Landesausstellung 2002, Bamberg, 9. Juli-20. Oktober 2002), hg. von Josef Kirmeier, Stuttgart.

Kitzinger, Beatrice (2013), „Illuminierte Wandlung: Te igitur-Initialen und Kanonbilder“, in: Ulricke Surmann und Johannes Schöer (Hgg.), Trotz Natur und Augenschein. Eucharistie - Wandlung und Weltsicht (Jahresausstellung „Art is Liturgy“ in Köln), Köln, 117-123.

Klemm, Elisabeth (2004), Die ottonischen und frühromanischen Handschriften der Bayerischen Staatsbibliothek. Katalog der illuminierten Handschriften der Bayerischen Staatsbibliothek in München, Bd. 2, Textband, Wiesbaden.

Kuder, Ulrich (1998), „Die Ottonen in der ottonischen Buchmalerei“, in: Gerd Althoff et al. (Hgg.), Herrschaftsrepräsentation im ottonischen Sachsen, Sigmaringen, 137-234.

LCI (1968): Lexikon der christlichen Ikonographie, 8 Bde., hg. von Engelbert Kirschbaum, Rom/ Freiburg/Basel/Wien.

Pippal, Martina (2010a), „Der Einband“, in: Sakramentar Heinrichs II. Handschrift Clm 4456 der Bayerischen Staatsbibliothek München (Kommentarband mit Beiträgen von Rolf Griebel u. a.), Gütersloh, 29-37. 
Pippal, Martina (2010b), „Die malerische Ausstattung“, in: Sakramentar Heinrichs II. Handschrift Clm 4456 der Bayerischen Staatsbibliothek München (Kommentarband mit Beiträgen von Rolf Griebel u. a.), Gütersloh, 51-123.

Pracht auf Pergament (2012), Pracht auf Pergament. Schätze der Buchmalerei von 780 bis 1180 (Katalog zur Ausstellung in der Kunsthalle der Hypo-Kulturstiftung München, 19. Oktober 2012-13. Januar 2013), hg. von Claudia Fabian, München.

Raff, Thomas (2008), Die Sprache der Materialien, Berlin.

Regensburger Buchmalerei (1987), Regensburger Buchmalerei. Von frühkarolingischer Zeit bis zum Ausgang des Mittelalters (Katalog zur Ausstellung der Bayerischen Staatsbibliothek München und der Museen der Stadt Regensburg, 16. Mai-9. August 1987), hg. von Florentine Mütherich und Karl Dachs, München.

Schreiner, Klaus (2000), „Buchstabensymbolik, Bibelorakel, Schriftmagie. Religiöse Bedeutung und lebensweltliche Funktion heiliger Schriften im Mittelalter und in der frühen Neuzeit“, in: Horst Wenzel, Wilfried Seipel und Gotthart Wunberg (Hgg.), Die Verschriftlichung der Welt. Bild, Text und Zahl in der Kultur des Mittelalters und der frühen Neuzeit, Wien / Mailand, 59-103.

Suntrup, Rudolf (1980), „Te igitur-Initialen und Kanonbilder in mittelalterlichen Sakramentarhandschriften“, in: Christel Meier und Uwe Ruberg (Hgg.), Text und Bild: Aspekte des Zusammenwirkens zweier Künste in Mittelalter und früher Neuzeit, Wiesbaden, 278-382.

Swarzenski, Georg (1901), Die Regensburger Buchmalerei des X. und XI. Jahrhunderts, Leipzig. Wittekind, Susanne (2009), Romanik (Geschichte der bildenden Kunst in Deutschland 2), München.

\section{Bildnachweise}

Abb. 1-5, 7, 11-13: Bayerische Staatsbibliothek München, Clm 4456.

Abb. 6: Donati, Angela / Gentili, Giovanni (Hgg.) (2005), Costantino il grande, la civiltà antica al bivio tra Occidente e Oriente (Ausstellungskatalog), Rimini, 259.

Abb. 8: Schreiner 2000, 73.

Abb. 9: Wikipedia. Art. „Grazer Buchtisch“, von Pondus - Eigenes Werk, CC BY-SA 3.0, https://commons. wikimedia.org/w/index. php?curid=8694771.

Abb. 10: Bayerische Staatsbibliothek München, Clm 4456, Foto des Autors.

Abb. 14: St. Emmeram zu Regensburg (Kleine Kunstführer 573), Regensburg: Schnell \& Steiner, $2007^{15}, 5$. 